\title{
أثر تنمية قدرات العاملين بالإرشاد بمحافظة المنوفية علي كفاءتهم المهنية
}

\author{
أحمد الهنيدي رضوان ، درية محمد خيري ، عصام سيد أحمد شاهين، \\ موسي أبو الحسن سليمان بركات
}

قسم الإرشاد الزراعي والإجتماع الريفي - كلية الزراعة - جامعة المنوفية

Received: Nov. 4, 2017

Accepted: Nov. 13,2017

الملخص

تستهدف الدراستة بصفة أساسية التعرف علي أثر تندية قدرات العاملين بالإرشاد الزراعي بدحافظة الدنوفية علي كفاءتهم المهنية. تم أخذ شاملة العاملين بالجهاز الإشادي بمحافظة المنوفية من الحاصلين علي مؤهلات زراعية بإجمالي 170 عاملا، وتم إختيار عينة عشوائية بسيطة عددها 120 عاملا بنسبة 70\% من العاملين , و قد تم جدع البيانات باستخدام الإستبيان بالدقابلة الثخصية، وتم إستخدم الإحصاء الوصفي وإختبار معامل الإرتباط البسيط ,والتحليل الإنحداري المتعدد المتدرج الصاعد. أظهرت النتائج أن كل من الدتغيرات الآتية له علاقة معنوية بالكفاءة الدهنية للعاملين بالإشاد الزراعي ببحافظة الدنوفية:

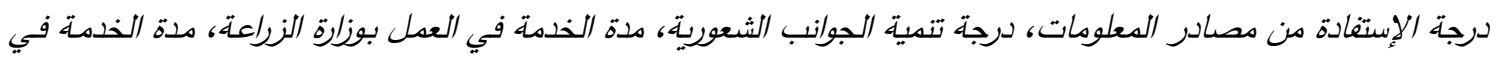

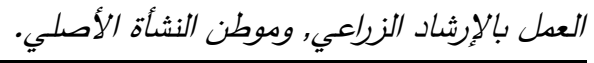

والجغرافية والإدارية وذلك من خلال خطة للتتمية البشرية

المقدمة

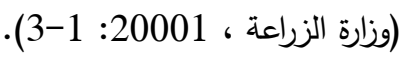

يعتبر القطاع الزراعي فى مصر أحد الدعائم الهامة للإقتصاد القومي، لذا كان من الضروري أن يولى إهتماما وتتجلى أهميـة تتمية قدرات العاملين بالإشـاد الزراعي

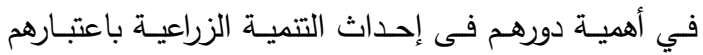

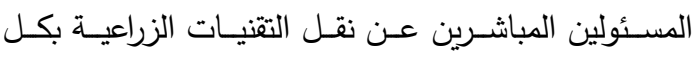

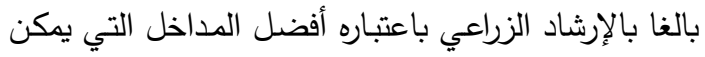

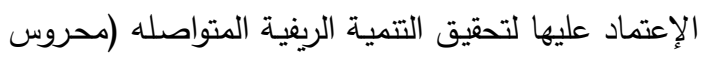

$$
\text { ووهبه ، 8:1996). }
$$

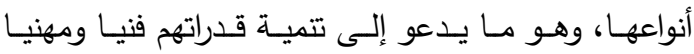

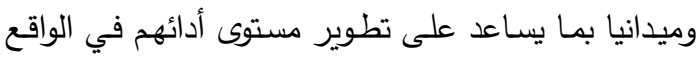
الميــداني (زاهـــر ، 1993 :250- الطنــوبى ,1998:

وقد أجرى هذا البحث على العاملين بالإرشاد الزراعي

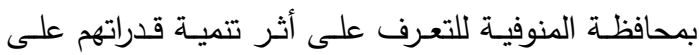

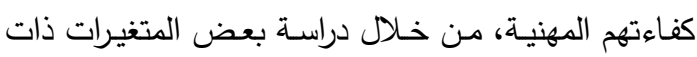
الصلة حتي يتمكن مخططوا ومنفذوا برامج تتمية القدرات مـن وضـعها في الإعتبـار عند تخطيط وتتفيذ البـرامج التتموية في المستقبل . ولا يتأتي ذلك إلا بتدعيم العمل الإرشادي الزراعي من

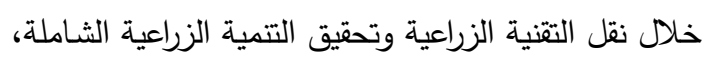
وذلك تأكيدا لسياسة وزارة الزراعة بعد تغيير الهيكل البنائي

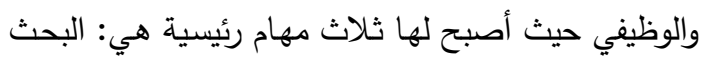
الزراعي، الإرشاد الزراعي، الدراسات الاقتصادية ( العادلي .(2: 1996 ، ونظرا لأهمية تتمية قدرات العاملين بالإرشاد الزراعي ،

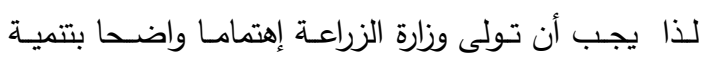

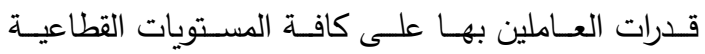




\section{A. E. Radwan, et al.,}

الإرشادي بمحافظة المنوفية من الحاصلين على مؤهلات

المشكلة البحثية

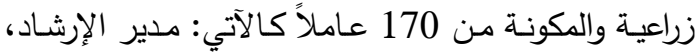

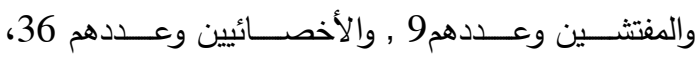
والمرشدين وعددهم 119مرشدا، والمهنسين تحت التدريب وعدده5, وتم إختيار عينة عشوائية بسيطة منهم بواقع

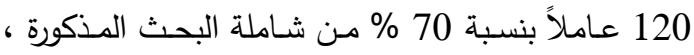

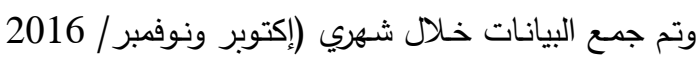
بطريقة الإستبيان بالمقابلة الثخصية.

\section{فروض الداسة}

لتحقيـق الهـدف الثالث مـن أهداف الدراسـة تـم صـياغة

$$
\text { الفروض النظرية التالية : }
$$

1-تساهم المتغيرات المستقلة المدروسة التالية: السن,ومدة

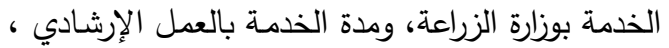

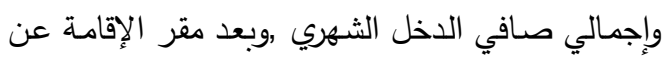
مكان العمل ,ومحل النشأة الأصلي، والمؤهل الدراسي، والتخصـص الدراسـي, ودرجـة الإسـتفادة مـن مصـادر

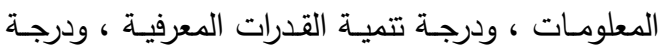
تتمية القدرات الأدائية ، ودرجة تتمية النواحي الثعورية

في تفسير التباين الحادث في درجة الكفاءة المعرفية.

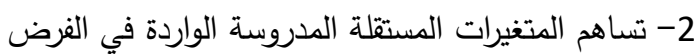

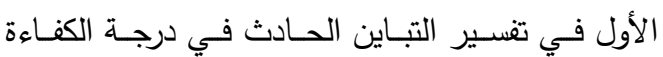

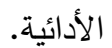

3 -تساهم المتغيرات المستقلة الددروسة الواردة في الفرض الادلة الأول في تفسير التبـاين الحسادث في درجـة الكفـاءة

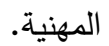

\section{أسلوب تحليل البيانات}

تم إسـتخدام الإحصــاء الوصـفي كـالتكرارات والنسـب المئوية، كما تم إستخدام مربع كاي لحساب دلالة الفروق الإق التحاب بين التكرارات والنسب المئوية والذي يقوم علي قياس مدي لئي إختلاف التكرارات الدتوقعة أو الدحتملة.

\section{متغيرات الاراسة}

ضمت الدراسة ثلاثة متغيرات تابعة وإثني عشر متغيرا مستقلا كالآتي :

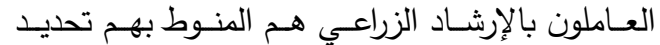
المشـاكل التتمويـة وتحليلهـا ووضـع خطــة لتتفيذ الحلـول ومتابعتها وتتييمها، وكل خطوة من هذه الخطوات ماهى إلا موقف إرشـادي يتطلب إعدادا مناسبا للقـائمين عليه (سويلم، 2015 : (315).

ونجاح العاملون بالإرشاد الزراعي في القيام بهذا الدور

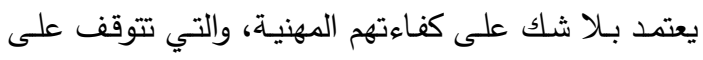

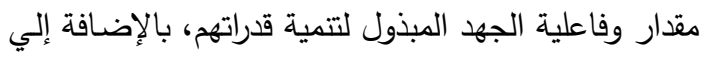
بعض المتغيـرات الثخصـية الأخـرى بجانب المتغيـرات الموقفية المحيطة بهم ( رشاد، 1996: 25). ونظرا لأن الدراسات السابقة في مجال الإششاد الزراعي - على كثرتها - لم تتطرق إلى هذا المجال على أهميته -

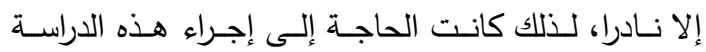

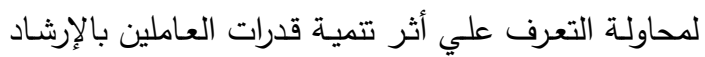
بمحافظة المنوفية علي كفاءتهم المهنية .

\section{أهداف الدراسة}

تستهدف الدراسة بصفة أساسية التعرف علي أثر تتمية قدرات العاملين بالإرشاد بمحافظـة المنوفيـة علي كفاءتهم المهنية وذلك من خلال تحقيق الأهداف الفرعية الآتية: 1- التعرف علي درجة كل من: الكفاءة المعرفية والكفاءة

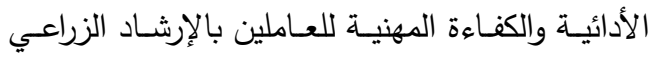
بمحافظة المنوفية.

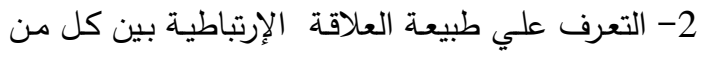

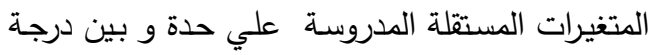

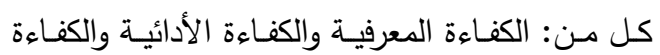
المهنية للعاملين بالإرشاد الزراعي بمحافظة المنوفية. 3- التعـرف علـي درجـة مســاهمة المتغيـرات المسـتقلة الدروسة مجتمعة في تفسير التباين الحادث في درجة

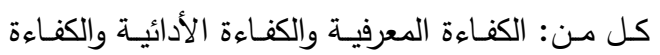
المهنية للعاملين بالإرشاد الزراعي بمحافظة المنوفية.

الإجراءات البحثية تم أخذ شاملة البحث الدكونة من العاملين بالجهاز 
المعرفي ودرجة إستفادته من هذه الدورات في حالة

حصوله عليها.

11- تتمية القدرات الأدائية: وتثير إلي عدد الدورات التي

حصل عليها المبحوث في الجوانب التنفيذية للعمل الإديل

الإشادي ودرجة إستفادته منها في حالة حصوله

عليها.

12 - تتمية النواحي الثعورية نحو العمل الإشادي:

ويقصد به الدرجة التي حصل عليها المبحوثين

نتيجة إجابتهم عن مجموعة من الأسئلة التي تدل

علي شعورهم نحو العمل الإشادي.

\section{نتائج البحث}

أولا: درجـة الكفـــاءة المعرفيـة والأدائيسـة والمهنيــة للعاملين يالإرشاد الزراعي بمحافظة المنوفية:

(1) أشارت النتائج الواردة بجدول (1) إلى أن نسبة 80\%

مـن العـاملين بالإرشــاد بالمحافظــة كانـت كفــــهم

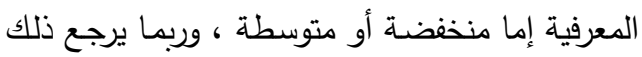

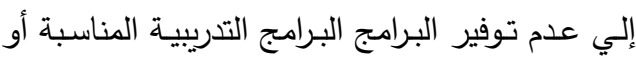
عدم إستفادة العاملين منها. (2) كما بينت النتائج الواردة بجدول (1) أن 77\% مـن العـاملين بالإرشـاد بمحافظـة المنوفيـة كانت كفـاءتهم

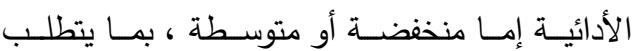
ضـرورة إعـادة النظــر في تفعيـل البـرامج التـريبيـة الموجهــة لرفــع الكفــاءة الأدائيــة للعـاملين وتــوفير التسهيلات المادية والمادة العلمية والكوادر المناسبة . (3) كمـــا أظهـرت النتـائج بجــول (1) أن 86\% مـن العاملين بالإرشاد الزراعي بمحافظة المنوفية كانت كفاءتهم المهنية إمـا منخفضــة أو متوسطة مـا يدل علـي ضـرورة تـوفير بـرامج تتميـة قدرات مناسـبة وتوفير الدعم المـادي والتسهيلات المادية بالإضـافة إلي مدربين كفء لرفع كفاء العاملين المهنية .
أ-المتغيرات التابعة

1 -درجة الكفاءة الدعرفية: ويقصد به درجة تحصيل المبحوث للمعلومات النظرية المتعلقة بالعمل الإرشادي والتي تشكل بناءه المعرفي بما ينعكس إيجابيا علي كفاءته في إنجاز عمله الإرشادئ. 2-درجة الكفاءة الأدائية: ويقصد به مدي قدرة العاملين بالإشاد الزراعي بمحافظة المنوفية علي إنجاز الأعمال الموكولة إليهم في أسرع وقت وبأقل تكلفة. 3- درجة الكفاءة المهنية: ويقصد به مجموع الدرجات التي حصل عليها الباحث في كل من المتغيرين التابعين

\section{ب - -المتغيرات المستقلة:}

1- السن: ويقصد به عمر البحوث أثناء جمع البيانات . 2- مدة الخدمة بوزارة الزراعـة : ويقصد بها مدة خدمـة

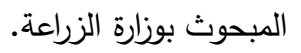

3- مدة الخدمة بالعمل الإرشادي : ويقصد بها مدة خدمة

$$
\text { المبحوث بالعمل الإرشادي. }
$$

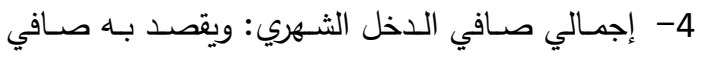
الدخل الشهري الذي يحصل عليه المبحوث من العمل

$$
\text { الإرشادي. }
$$

5- بعد مقر الإقامة عن مكان العمل: ويشير إلي المسافة بالكيلومتر من مقر الإقامة إلي مكان العمل.

6- محل النشأة الأصلي: ويقصد به محل نشأة المبحوث الإفه إله ريفي أم حضري. 7- المؤهل الدراسي: ويقصد به المؤهل الدراسي الذي حصل عليه المبحوث. 8- التخصص الدراسي: ويقصد به التخصص الدراسي

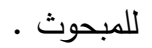
9- درجة الإستفادة من مصادر المعلومات: وتشير إلي درجة إستفادة المبحوث من مصادر المعلومات ذات الصلة بالإرشاد الزراعي لإنجاز عمله الإرشادي.

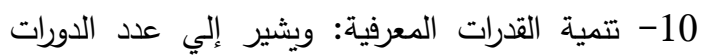
التدريبية التي حصل عليها المبحوث في المعلومات النظرية التي تتصل بعمله الإشادي لدعم بناءه 
جدول رقم (1) توزيع المبحوثين وفقاً لارجة كفاءتهم المعرفية والأدائية ودرجة كفاءتهم المهنية.

\begin{tabular}{|c|c|c|}
\hline النسبة\% & 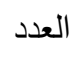 & درجة الكفاءة \\
\hline & & 1- درجة الكفاءة المعرفية: \\
\hline 20 & 24 & منخفض \\
\hline 60 & 72 & متوسط \\
\hline \multirow[t]{2}{*}{20} & 24 & 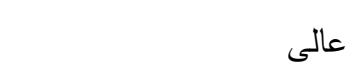 \\
\hline & & 2- درجة الكفاءة الأدائية: \\
\hline 18 & 21 & منخفض \\
\hline 69 & 83 & متوسط \\
\hline \multirow[t]{2}{*}{13} & 16 & 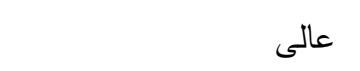 \\
\hline & & 3- درجة الكفاءة المهنية: \\
\hline 31 & 37 & منخفض \\
\hline 55 & 66 & متوسط \\
\hline 14 & 17 & 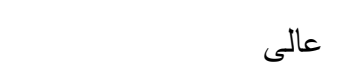 \\
\hline
\end{tabular}

الإرشادى، ومدة الخدمة بوزارة الزراعة، وبين المتغير التابع

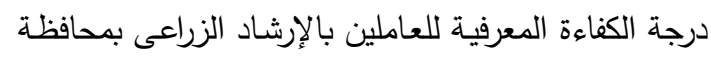

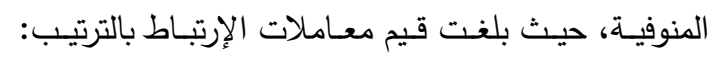

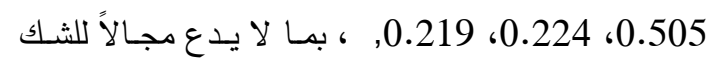

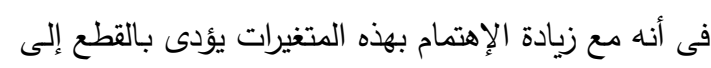

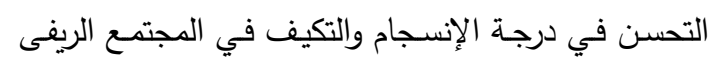
بين العاملين بالإششاد والزراع على مختلف فئاتهم.

(2) العلاقـة بـين درجـة الكفـاءة الأدائيسة وبين كل مسن المتغيرات المستقلة:

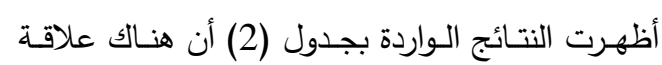
طردية ومعنوية عند مستوى (0.01) بالمتغيرات المتعلقة
ثانيا: العلاقة بين المتغيرات المستقلة وبين كل من الكفــاءة المعرفيـة والكفــاءه الأدائيـة وإلكفــاءة المهنية :

تم استخدام معامل الإرتباط البسيط للتعرف علي نوع العقائ العلاقــة الإرتباطيـة بـين المتغيـرات المسـتقلة والمتغيـرات التابعة كالآتي: (1) العلاقـة بين درجـة الكفـاءة المعرفيـة وبين كل مـن المتغيرات المستقلة: تبين النتائج الـواردة بجدول (2) أنسه توجد علاقـة طردية ومعنويـة عند مستوى (0.01) بالمتغيرات المتعلقة

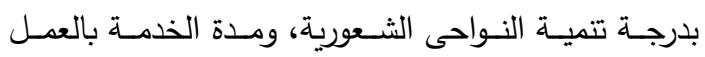


المتعلقة بدرجـة تتميـة النواحي الثـعورية، ودرجـة الإستفادة

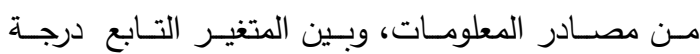
الكفـاءة المهنيـة ، حيـث بلغــت قـيم معساملات الإرتبـاط بالترتيـبـ: 0.533، 0.53, كمـــا بينــت النتـائج وجـود علاقـة طرديـة ومعنويـة عند مستوى (0.05) بمتغير مدة الخدمة بوزارة الزراعـة وبين درجة الكفاءة المهنية كمتغير التـابع ، حيـث بلغــت قيمـة معامـل الإرتبـاط: 0.174 ، 0. الأمر الذي يثير إلى أن زيـادة هذه المتغيرات يؤدى إلى الإنى

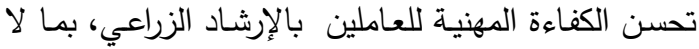

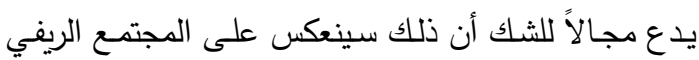
من حيث تحسن العلاقة بين الإرشاد والزراع. بينما جاءت العلاقة بباقي المتغيرات المستقلة المدروسة غير معنويـة .
بدرجـة تتميـة النـواحي الثـعورية، ودرجـة الإسـتفادة مـن مصسادر المعلومـات، وبـين المتغيـر التـابع درجـة الكفـاءة الأدائيـة ، حيث بلغـت قيم معـاملات الإرتبـاط بالترتيـب: 0.484، 0.258, الأمــر الـــي يشـير إلـــى أن زيـــادة الإهتمـام بهذه المتغيرات يؤدى بـالقطع إلى تعلم الريفيين المهارات الجديدة من العاملين بالإرشاد الزراعي مما يؤدى إنى إلى زيادة الإنتاج وزيادة دخولهم مما ينعكس على المجتمع لياه ككل.

(3) العلاقـة بـين درجـة الكفـاءة المهنيـة وبـين كل مسن المتغيرات المستقلة:

تبين مسن النتائج الـواردة بجدول رقـم (2) أن هنـاك علاقـة طرديـة ومعنويـة عند مستوى (0.01) بـالمتغيرات

جدول رقم (2): قيم معاملات الإرتباط البسيط بين المتغيرات المستقلة المدروسـة وبين درجة الكفاءة المعرفية والأدائية ودرجة الكفاءة المهنيه.

\begin{tabular}{|c|c|c|c|c|}
\hline \multicolumn{3}{|c|}{ قيم معاملات الإرتباط البسيط } & \multirow[t]{2}{*}{ المتغيرات المستقلة } & \multirow[t]{2}{*}{ r } \\
\hline درجة الكفاءة & درجة الكفاءة & درجة الكفاءة & & \\
\hline 0.163 & 0.133 & 0.177 & عمر المبحوث & \\
\hline$* 0.174$ & 0.122 & $* * 0.219$ & مدة الخدمة بوزارة الزراعة & 2 \\
\hline 0.169 & 0.110 & $* * 0.224$ & مدة الخدمة بالعمل الإرشادي & 3 \\
\hline 0.054 & 0.052 & 0.049 & الدخل الشهري للمبحوث & 4 \\
\hline $0.084-$ & $0.084-$ & 0.015 & التكاليف الشهرية للإنتقالات & 5 \\
\hline$* * 0.248$ & $* * 0.258$ & 0.105 & درجة الإستفادة من مصادر المعلومات & 6 \\
\hline 0.105 & 0.072 & 0.105 & درجة الإستفادة من الدورات التدربيية لتتمية القدرات المعرفية & 7 \\
\hline 0.170 & 0.160 & 0.170 & درجة الإستفادة من الدورات التدريبية لتتمية القدرات الأدائية & 8 \\
\hline$* * 0.533$ & $* * 0.484$ & $* * 0.505$ & درجة تتمية النواحى الشعورية & 9 \\
\hline
\end{tabular}




\section{A. E. Radwan, et al.,}

المتـدرج الصـاعد لإختبـار صـحة هذا الفرض، و تشير النتائج الواردة بجدول رقم (4) إلي وجود متغيرين إثنين

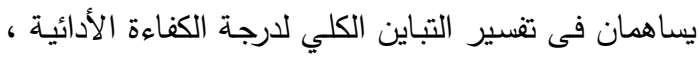

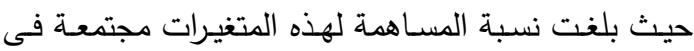

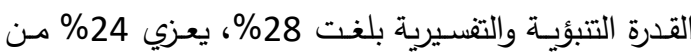
الدرجة الإجمالية للمساهمة إلى متغير درجة تنمية النواحي الشعورية ، و 4\% إلى متغير درجة الإستفادة من مصادر المعلومات ، ولإختبار معنوية درجة المساهمة تم إستخدام F إختبار " ف " لمعنوية معامل الإنحدار حيث بلغت قيمة " 22.632 " F أمكن رفض الفرض الإحصائي المتعلق بالفرض النظري الثاني بالنسبة للمتغيرات المستقلة -سالفة الذكر -والتي التئي

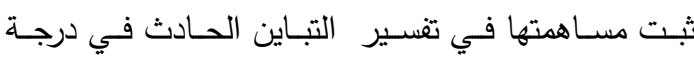

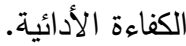

3- لتحديد درجة مساهمة المتغيرات المستقلة في تفسير التباين الحادث في درجة الكفاءة المهنية : كان من الضروري إختبار الفرض النظري الثالث

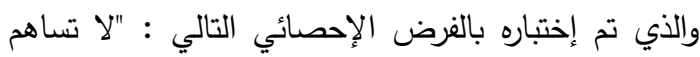

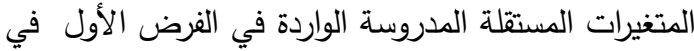
تقسير التباين الحادث في درجة الكفاءة المهنية." وقد تم إستخدام نموذج التحليل الإرتباطي والانحداري المتعدد المتدرج الصاعد لإختبار صحة هذا الفرض، و تثير النتائج الواردة بجدول رقم (5) إلي وجود ثلاث متغيرات

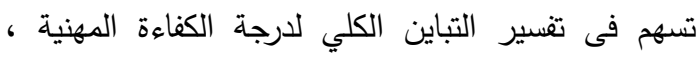
حيث بلغت نسبة إسهام هذه المتغيرات مجتمعة في القدرة

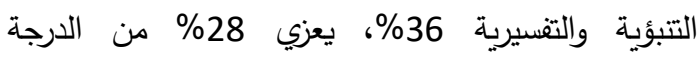
الإجمالية للمساهمة إلى متغير درجة تتمية النواحي الشعورية ، و 5\% إلى متغير مدة الخدمة في العمل الإرشادي ، و 3\% إلى متغير درجة الإستفادة من مصادر المعلومات، ولاختبار معنوية درجة المساهمة تم إستخدام

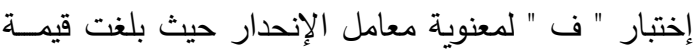
21.778 " F "

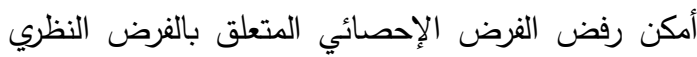
الثالث بالنسبة للمتغيرات المستقلة سالفة الذكر - والتي ثبت مساهمتها في تفسير التباين الحادث في درجة الكفاءة المهنية.
ثالثا: درجة مساهمة المتغيرات المستقلة المدروسة مجتمعة في تفسير التباين الحادث في كل من المتغيرات التابعة

1-تتديد درجة مساهمة المتغيرات المستقلة في تفسير التباين الحادث في درجة الكفاءة المعرفية:

كان من الضروري إختبار الفرض النظري الأول والذي

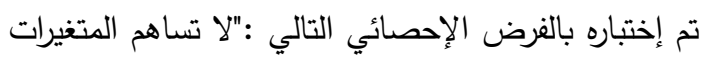
المستقلة المدروسة التالية: السن، ومدة الخدمة بوزارة الزراعة ، ومدة الخدمة بالعمل الإرشادي ، وإجمالي صافي التئل

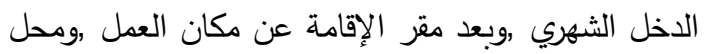

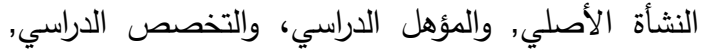
ودرجة الإستفادة من مصادر المعلومات ، ودرجة تتمية الإلية القدرات المعرفية , ودرجة تتمية القدرات الأدائية ، ودرجة

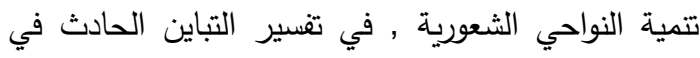
درجة الكفاءة المعرفية " وقد تم إستخدام نموذج التحليل الإرتباطي والإنحداري المتعدد المتدرج الصاعد لإختبار

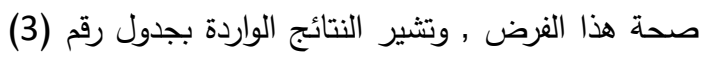
وجود متغيرين إثين يساهمان في تفسير التباين الكلي لدرجة الكفاءة المعرفية حيث بلغت نسبة إسهام هذه فئن المتغيرات مجتمعة فى القدرة التتبؤية والتفسيرية بلغت

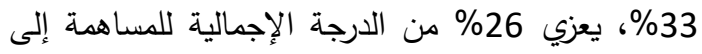

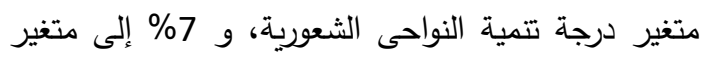
مدة الخدمة فى العمل الإرشادى, ولاختبار معنوية درجة لئه

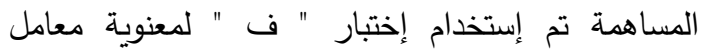
الإنحدار حيث بلغت قيمة " F " 28.700 وهى معنوية عند مستوي (0.01) ، وبذلك أمكن رفض الإن الفرض

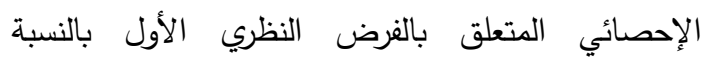
للمتغيرات المستقلة سالفة الذكر -والتي ثبت مساهمتها في الإني

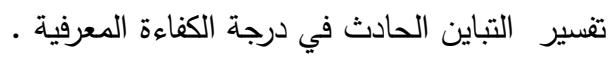

2- لتحديد درجة مساهمة المتغيرات المستقلة في تفسير التباين الحادث في درجة الكفاءة الأدائية : كـان مـن الضـروري إختبـار الفـرض النظـري الثـاني

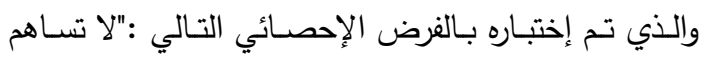

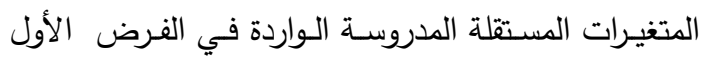

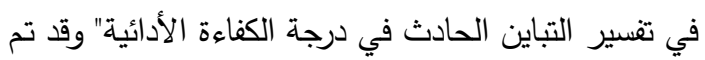

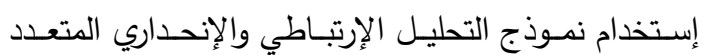


جدول رقم (3): نتائج التحليل الانحداري المتعدد التدريجي الصـاعد لتحديد مسـاهمة المتغيرات المستقلة المدروسـة من

النوع الفتري في درجة الكفاءة المعرفية.

\begin{tabular}{|c|c|c|c|c|c|}
\hline إختبار معنوية معامل فحسوبة & معامل التحديد & معامل التحديد & معامل الإرتباط & المتغيرات المستقلة المؤثرة في & التحليل \\
\hline$* * 39.978$ & 26 & 0.255 & 0.505 & درجة تتمية النواحى الشعورية & الأولى \\
\hline$* * 28.700$ & 7 & 0.331 & 0.575 & مدة الخدمة بالعمل الإرشادى & الثانية \\
\hline
\end{tabular}

جدول رقم (4): نتائج التحليل الانحاري المتعدد التدريجي الصاعد لتحديد مساهمة المتغيرات المستقلة في درجة الكفاءة الأدائية.

\begin{tabular}{|c|c|c|c|c|c|}
\hline 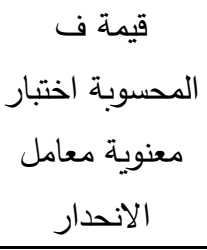 & معامل التحديد & معامل التحديد & معامل الارتباط & في المتغيرات المستقلة المؤثرة & خطوات التحليل \\
\hline$* * 35.870$ & 24 & 0.24 & 0.484 & درجة تتمية النواحى & الأولى \\
\hline$* * 22.632$ & 4 & 0.28 & 0.530 & درجة الإستفادة من مصادر & الثانية \\
\hline
\end{tabular}

جدول رقم (5): نتائج التحليل الانحاري المتعدد التدريجي الصاعد لتحديد مساهمة المتغيرات المستقلة المدروسة من النوع الفتري في درجة الكفاءة المهنية.

\begin{tabular}{|c|c|c|c|c|c|}
\hline 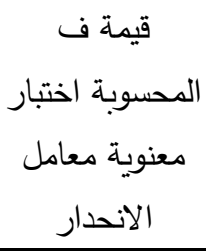 & معامل التحديد & معامل التحديد & معامل الارتباط & المتغير المستقل الداخل & 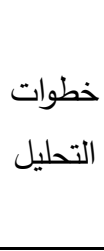 \\
\hline$* * 46.309$ & 28 & 0.28 & 0.533 & درجة تنمية النواحى & الأولى \\
\hline$* * 29.023$ & 5 & 0.33 & 0.578 & مدة الخدمة بالعمل & الثانية \\
\hline$* * 21.778$ & 3 & 0.36 & 0.602 & درجة الإستفادة من & الثالثة \\
\hline
\end{tabular}




\section{A. E. Radwan, et al.,}

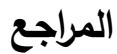

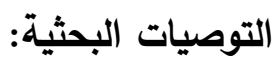

1. العادلي ، احمد السيد ، "مجالات العمل الإرشادي الزراعي

وبنـاءا علي النتائج أوصـت الدراسـة باعتمـاد مفهوم

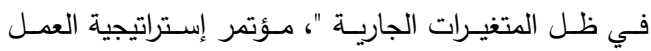

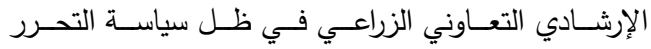

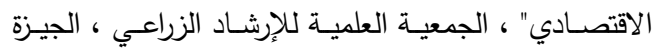

$$
\text { .1996/11/28, 27، }
$$

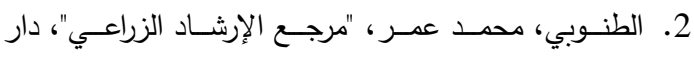

النهضة العربية للطباعة والنشر، بيروت، 1998.

3. رشاد ، سعيد عباس محمد، "الإحتياجات التدريبية للمرشدين

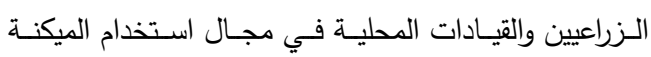

الزراعية بمحافظة القليوبية", رسالة ماجستير غير منشورة ،

كلية الزراعة بشتهر ، جامعة الزقازيق، فرع بنها، 1991.

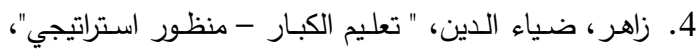
دار سعاد الصباح، الكويت، 1993.

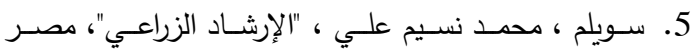

للخدمات العلمية، القاهرة، 1997.

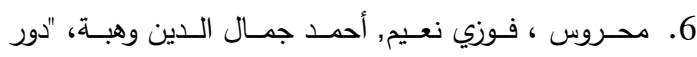

الإرشاد الزراعي في مجالات الثقافة السكانية وصيانة البيئة

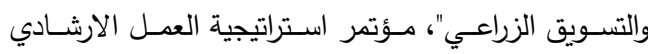

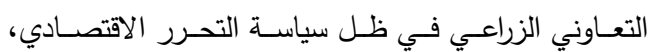

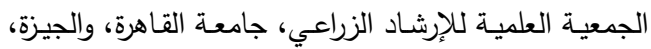

$.1996-11-28,27$

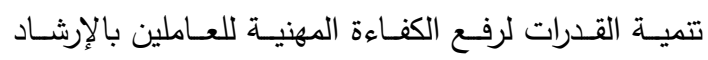
الزراعي بمحافظة المنوفية لما له من دلالة أشمل من دلالة مفهوم التدريب حيث تنظر الدراسة للتدريب علي أنه أحد وسائل تتمية القدرات، كما أوصت الدراسـة بدعم الإرشـاد الزراعي بالمحافظة بعنصر الثباب، حتي تتنقل إليهم خبرة

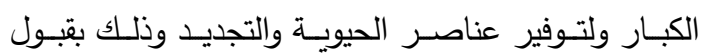
تعيينات جديدة بالإرشاد الزراعي بالمحافظة, كما أوصت الدراسة بدعم الإرشاد الزراعي بالمحافظة بتخصصين في لإساري

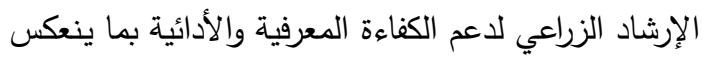

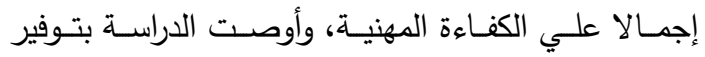

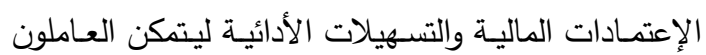
بالإرشاد من الإستفادة من مصـادر المعلومـات المختلفة, كما أوصت الدراسة باعتبار المتغيرات الآتية عند إختيار

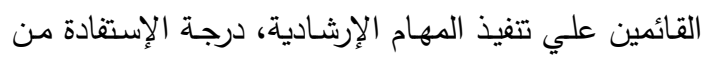
مصادر المعلومات، ودرجة تتمية النواحي الثعورية تجاه

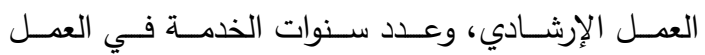
الإرشادي, وعدد سنوات الخدمة في وزارة الزراعة، ومحل

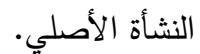

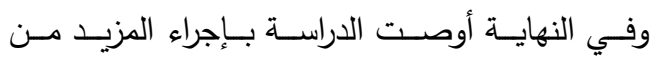
الدراسات للتعرف علي باقي القدرات التي يتطلبها العمل

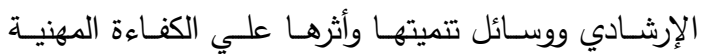
للعاملين بالإرشاد الزراعي بمحافظة المنوفية . 


\title{
PERSONNEL ABILITIES IN MINOUFIYA GOVERNORATE AND ITS EFFECT ON THEIR PROFESSIONAL COMPETENCE
}

\author{
A. E. Radwan, Dorria M. Khairy, E. S. A. Shaheen, M. A. S. Baraka \\ Department of Agricultural Extension and Rural Community Faculty of Agriculture, \\ Minoufiya University
}

\begin{abstract}
Agricultural extension personnel are responsible for the development processes in the agricultural sector as a step on the road to comprehensive development, so the development of professional competence is a necessary requirement. .

Therefore, this study was to identify the effect of the development of extension personnel abilities in Minoufiya governorate on their professional competence through the following objective:

1- Identify the cognitive competence of agricultural extension personnel in minoufiya governorate

2- Identify the operational competence of agricultural extension personnel in Minoufiya governorate.

3- Identify the professional competence of agricultural extension personnel in minoufiya governorate

This was done through a search form designed specifically for this purpose, has been filled through personal interviews of respondents work after preliminary tests on them had been reached, that each of the following variables positively affect on the efficiency of agricultural extension personnel:

1-The degree of benefit from the information sources.

2-The degree of development of emotional aspects

3- Number of years of work at the ministry of agriculture.

4- Number of years of work at the agricultural extension

5-Original place of origin.

The study recommended also further studies to identify the capabilities that affect on the competence of agricultural extension personnel and means of it.
\end{abstract}

Key words: Development, extension, competence, abilities.

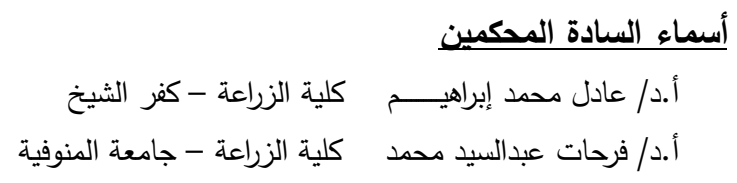

